\title{
Individual motor unit analysis in the diagnosis of disorders of urethral sphincter innervation
}

\author{
CLARE J FOWLER, R S KIRBY, M J G HARRISON, E J G MILROY, \\ R TURNER-WARWICK \\ From the Departments of Neurology and Urology, The Middlesex Hospital, London, UK
}

SUMMARY A technique is described for recording the electromyographic activity of striated muscle in the urethral sphincter. Using a concentric needle electrode and an oscilloscope with a delay line and trigger, individual motor units were isolated and measured. To validate the method as a means of detecting pathology, the results are presented of analysis of the motor units of a group of patients with disturbances of micturition, known to have either cauda equina lesions or pelvic nerve injury. These results are compared with those from a group of controls. In the control group $93 \%$ of the motor units were less than $6 \mathrm{~ms}$ in duration and $2.0 \mathrm{mv}$ in amplitude. Of motor units recorded from patients with cauda equina or pelvic nerve injury $59 \%$ exceeded the control ranges for amplitude or duration. It is concluded that quantitative analysis of individual motor units may be a helpful technique in the investigation of patients with disorders of micturition.

The urethral sphincter in both male and female is composed of a combination of smooth and striated muscle fibres. In females, the striated muscle fibres are aggregated in the midurethral segment and encircle the urethra. In males they are at the apex of the prostrate distal to the veru montanum.'

Electromyography (EMG) of the striated muscle of the urethral sphincter was introduced in 1955 by Franksson and Petersen ${ }^{2}$ who used two needle electrodes to record patterns of motor unit firing in the muscle. Although others used concentric needle electrodes to study urethral EMG activity ${ }^{3-6}$ their interest lay more in overall sphincter activity and reflex latencies rather than on analysis of individual

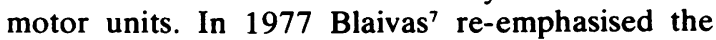
value of urethral sphincter EMG in the evaluation of disturbances of micturition. He noted the importance of recognising prolonged polyphasic motor units as evidence of reinnervation of the muscle.

In 1953 Buchthal and Pinelli ${ }^{8}$ described a technique for measuring the parameters of individual motor unit potentials recorded from skeletal muscle, when photographed firing singly in an interference pattern during minimal contraction. FuglsangFrederiksen et al $^{910}$ reported the changes in amp-

Address for reprint requests: Dr Clare Fowler, Reta Lila Weston Institute of Neurological Studies, Middlesex Hospital Medical School, London W1N 8AA, UK

Received 25 October 1983. Accepted 8 December 1983 litude and duration characterising myopathic disease and the changes in the motor unit due to denervation and reinnervation. The introduction of a signal trigger and delay line" greatly facilitated the ease with which individual motor units could be isolated from the interference pattern.

In general EMG practice the method of individual motor unit analysis is often regarded as being time consuming and giving an unrepresentative picture of the state of the whole muscle. However, the urethral sphincter muscle is small and is comprised of tonically firing motor units and the technique is particularly suited in this instance.

To validate the usefulness of this technique as a method of recognising injury to the innervation of the urethra we have examined spontaneously firing units from the sphincter muscle in cases known to have a neurological cause for their bladder dysfunction. Results from this group of patients are compared with those from a control group.

\section{Patients}

The control group consisted of 10 subjects. There were eight males and two females and the age range was from 23 to 69 years with a mean of 53 . These were patients who were in the urological ward undergoing surgery of the upper urinary tract, with the exception of three men (aged between 64-69) who were to have transurethral resections for prostatic hypertrophy. All subjects gave informed consent. 
Table Details of patients with known neurological lesions

\begin{tabular}{|c|c|c|c|c|c|}
\hline Patient & Sex & $\begin{array}{l}\text { Age } \\
(y r)\end{array}$ & $\begin{array}{l}\text { Cause of S2-S4 } \\
\text { innervation } \\
\text { injury }\end{array}$ & Duration & $\begin{array}{l}\text { Nature of bladder } \\
\text { dysfunction }\end{array}$ \\
\hline 1. FA & $\mathbf{M}$ & 38 & Cystercercosis & 3 months & Areflexic bladder \\
\hline 2. BT & $\mathbf{M}$ & 43 & $\begin{array}{l}\text { Damage to cauda } \\
\text { equina at } \\
\text { laminectomy }\end{array}$ & & Areflexic bladder \\
\hline 3. ET & $\mathbf{M}$ & 44 & $\begin{array}{l}\text { Neurofibroma of } \\
\text { sacral canal }\end{array}$ & 13 yrs & Areflexic bladder \\
\hline 4. RS & $\mathbf{M}$ & 37 & $\begin{array}{l}\text { L4/L5 central } \\
\text { disc prolapse }\end{array}$ & 3 yrs & Areflexic bladder \\
\hline 5. JH & F & 28 & $\begin{array}{l}\text { L4/L5 central } \\
\text { disc prolapse }\end{array}$ & $1 \mathrm{yr}$ & Areflexic bladder \\
\hline 6. EC & $\mathbf{M}$ & 56 & $\begin{array}{l}\text { Damage to cauda } \\
\text { equina from } \\
\text { injection of } \\
75 \% \text { alcohol }\end{array}$ & 3 yrs & Areflexic bladder \\
\hline 7. EC & $\mathrm{F}$ & 58 & $\begin{array}{l}\text { Abdomino- } \\
\text { perineal } \\
\text { resection of } \\
\text { rectum }\end{array}$ & 6 months & Areflexic bladder \\
\hline 8. BT & $\mathbf{F}$ & 75 & $\begin{array}{l}\text { Abdomino- } \\
\text { perineal } \\
\text { resection of } \\
\text { rectum }\end{array}$ & 3 yrs & Areflexic bladder \\
\hline
\end{tabular}

Five patients with cauda equina lesions (mean age 41 , range 38-55 years), and two patients with pelvic nerve injury, aged 58 and 75 were studied. The details of the underlying causes of neural injury and the duration of symptoms are given in the table.

\section{Method}

In male patients the electrode was inserted with the subject in the left lateral position with flexed knees. Women lay supine with hips flexed and abducted. A concentric needle electrode (Disa) $30 \mathrm{~mm}$ length, tip diameter $0.45 \mathrm{~mm}$ was used. In male subjects the needle was introduced through the perineum in the midline and the tip guided to the level of the apex of the prostate by a finger in the rectum. In female patients the electrode was inserted at a point $1 \mathrm{~cm}$ lateral to the urethral meatus and guided towards the midline. Positioning of the needle tip was aided by listening to the audio output from the electrophysiological recording unit (Medelec MS6). No patient found the procedure unduly distressing, and after the initial penetration of the skin complained of minimal discomfort.

The units captured for analysis were only those spontaneously firing. The level of tonic motor unit activity in the urethral sphincter is related to the degree of bladder filling. ${ }^{12}$ All patients were requested to attempt to empty their bladders just before the examination.

A mean of seven motor units were analysed from each patient, with a maximum of 12 . The small size of the muscle, particularly in females, limited the number of needle position changes that could be made.

Using a delay line and signal triggering individual motor units were identified. A unit was recorded on lightsensitive paper, either by repeated superimposition or in "falling leaf" display. The consistency of waveform seen on examining a motor unit confirmed that a potential was due to the activity of a single motor unit rather than superimposition of several units. This was of particular importance when units had late components and were of complex waveform.

The duration and amplitude of individual units was measured from film. The number of phase reversals of voltage of more than $100 \mu \mathrm{V}$ were counted. A unit was considered to be polyphasic if there were more than five phase reversals.

The results are presented in the form of 3-dimensional histograms (figures 5 and 6). These were prepared using a data management program (dBase II Ashton Tate), and transferring the data to standard data format files. The points were then read by a plotting program written in Microsoft Basic. An Osborne I microcomputer interfaced to a Hewlett-Packard plotter was used.

\section{Results}

(1) Normal interference pattern: Tonically firing motor units were found in patients from all groups. Patients were unable to suppress the tonic firing activity which is known to be related to the degree of bladder filling. ${ }^{2}$ It was not possible therefore to identify fibrillation potentials in otherwise electrically silent muscle, as may be done for the recognition of denervation in skeletal striated muscle. There was one exception to this. This patient had recently suffered a complete cauda equina lesion, with dense sacral anaesthesia and no anal tone. There were no tonically firing units and attempts at voluntary effort did not activate any units. Only in this patient were fibrillation potentials identified.

In all control subjects an increase in the interference pattern was produced by asking the patient to "squeeze" or by stopping micturition in midstream. No attempt has been made to quantitate the interference patterns, since their fullness is critically dependent on the position of the electrode tip within the rather small volume of muscle. However in those patients with cauda equina lesions or pelvic nerve injury, the interference pattern appeared less full on maximal voluntary effort despite repositioning the needle.

(2) Parameters of normal and abnormal motor units: Examples of traces from normal and pathological cases are shown in figs 1-4. Figure 1 is an example of a motor unit recorded from a control subject. Figs 2-4 were all recorded from patients known to have suffered damage to the cauda equina. Figure 2 shows a polyphasic unit of long duration with "satellite" components. Figure 3 shows a unit of greatly increased amplitude and fig 4 , a unit with unstable components, indicating immaturity of regenerating axons innervating part of the unit.

Figures 5 and 6 show 3-dimensional histograms characterising the motor units recorded from each 


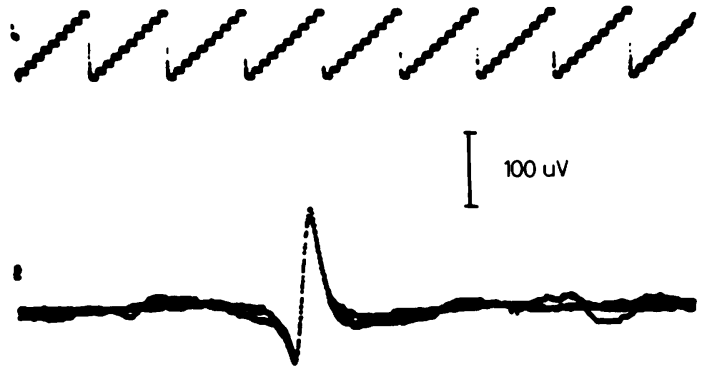

Control MA

Fig. 1 A motor unit recorded from a control subject.

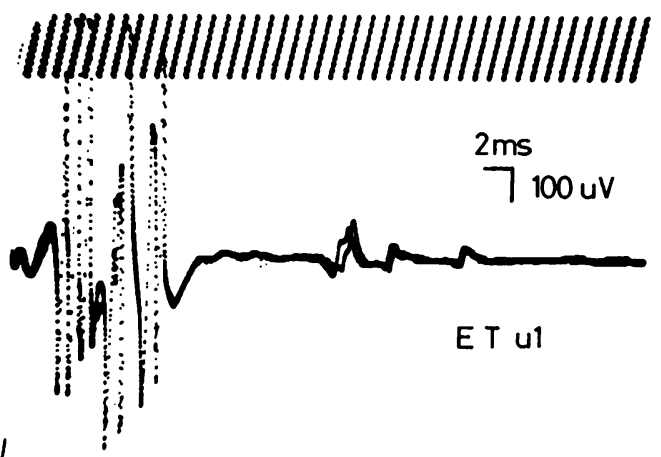

Fig. 2 A motor unit of prolonged duration.
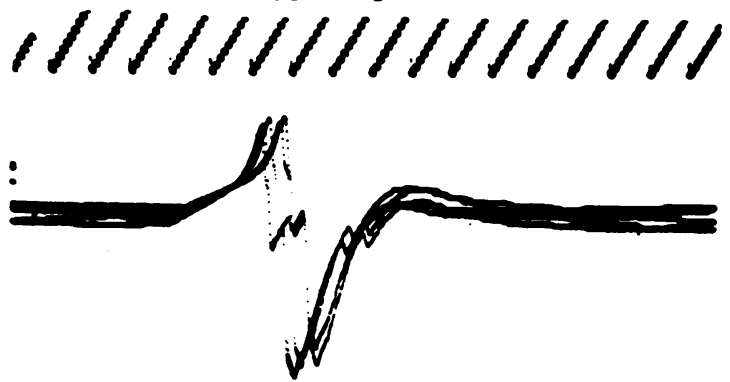

RT u8
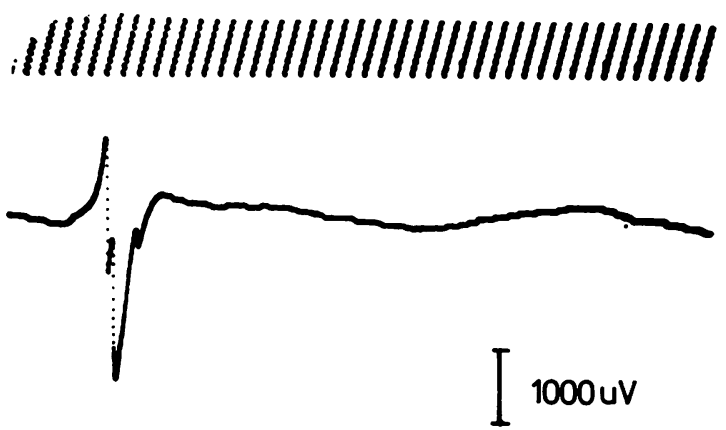

Fig. 3 A motor unit of increased amplitude.
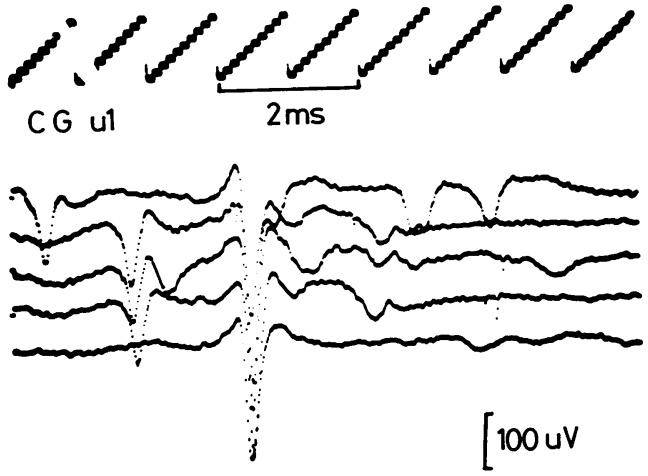

Fig. 4 A motor unit showing instability.

group. Figure 5 shows the characteristics of the motor units recorded from the control group. Ninety three percent of the units were less than $6 \mathrm{~ms}$ in duration and less than $2000 \mu \mathrm{V}$ in amplitude. Six of the 80 units were outside these limits; two were both polyphasic and of prolonged duration, presumably indicating the existence of pathological units in this control group. Both these units were found in elderly men awaiting prostate surgery. Three other units were statistical "outliers".

Figure 6 shows the motor units recorded from the patients known to have cauda equina or pelvic nerve lesions. Fifty nine percent of the units are either prolonged or increased in amplitude compared with the control range.

\section{Discussion}

Gosling $e a^{13}$ have shown that the striated muscle of the distal urethral sphincter is made up of fibres considerably smaller in diameter than those of the adjacent periurethral muscles in the levator ani. The electrophysiological finding of relatively low amplitude and short duration motor units in the control subjects is consistent with this anatomical data. Excluding the five units which were either statistical outliers or pathological, the mean amplitude of the motor units was $563 \mu \mathrm{V}$, with a mean duration of $2.8 \mathrm{~ms}$. These results are in keeping with the report of Jessel et $\mathrm{l}^{14}$ that sphincter motor units are smaller than skeletal muscle units, with a mean amplitude between 200 and $600 \mu \mathrm{V}$. Neill and Swash's also report low amplitude motor units in the external anal sphincter.

The difference between the characteristics of the control group and the group with cauda equina lesions or peripheral nerve injury, depend on demonstrating changes which indicate reinnervation has occurred. Reinnervation by collateral sprouting 


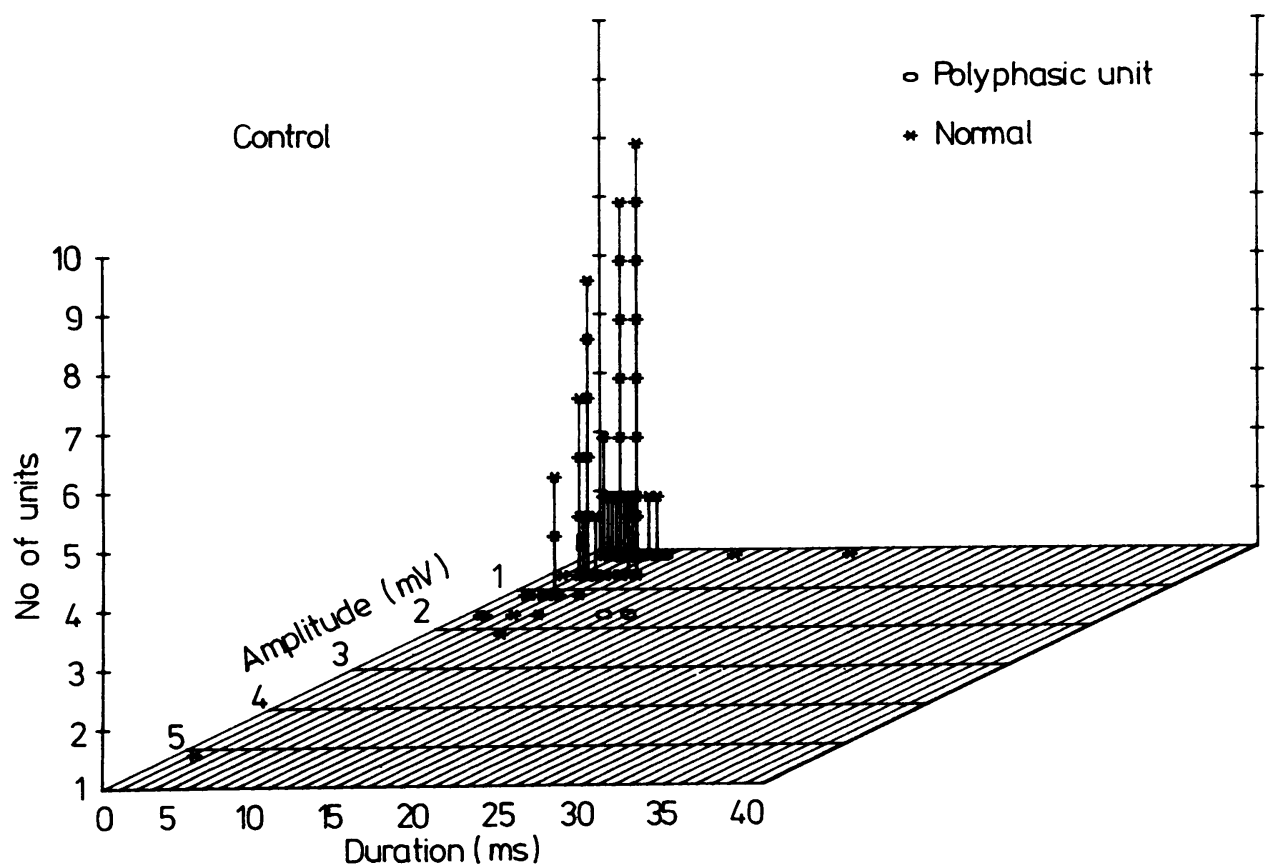

Fig. 5 A 3-dimensional histogram showing the distribution of motor units for amplitude and duration, recorded from control subjects.

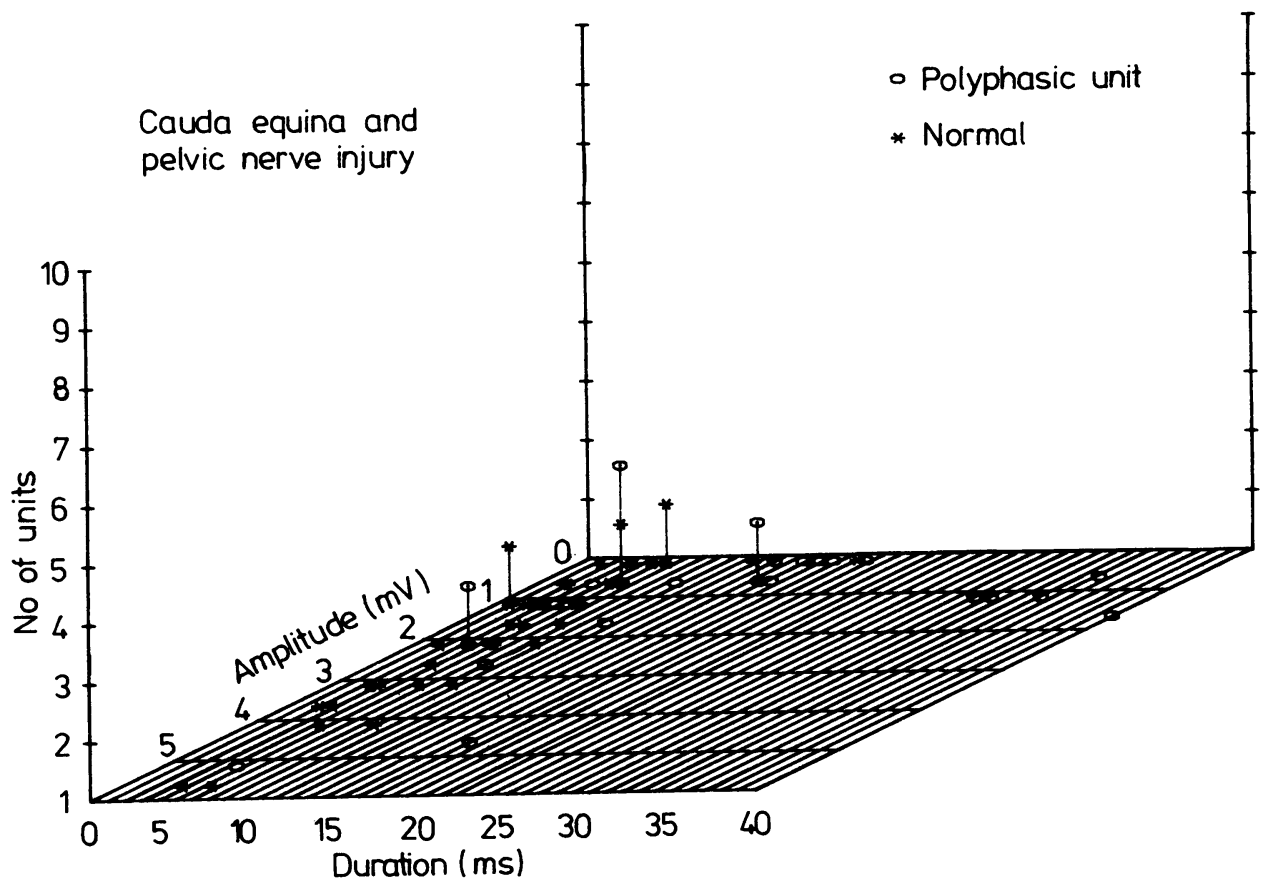

Fig. 6 A 3-dimensional histogram showing the distribution of motor units for amplitude and duration, recorded from patients with either cauda equina or pelvic nerve injury. 
or by nerve regrowth is unlikely to produce changes in less than a few months. This test cannot therefore be expected to demonstrate an abnormality immediately after the onset of an injury.

Except for the impression of a reduced interference pattern on voluntary contraction which may depend to some extent on the precise position of the needle, no positive evidence of denervation is demonstrated by this technique, which depends on the identification of changes brought about by reinnervation. The exception to this was the single patient with an electrically silent muscle in whom fibrillation potentials were seen.

The principle of m.u. analysis has already been applied to units recorded from the anal sphincter in motor neuron disease and Shy Drager syndrome, ${ }^{16}$ and Neill and Swash ${ }^{15}$ have examined the fibre density of motor units in the anal sphincter with single fibre EMG to demonstrate reinnervation.

Criticism has been levelled against the method on the grounds that the precise position of the needle tip is uncertain and that the units recorded may be in the periurethral striated muscle rather than the intramural striated muscle of the urethra. However, for the purpose of excluding neurological damage to the sacral 2,3 and 4 innervated musculature the validity of this method remains even were the needle sometimes not to be in the rhabdosphincter.

We suggest that the main use of this technique is in the exclusion of a neurological lesion in patients with a prolonged history of incontinence or retention, in whom it may obviate the need for more invasive neurological investigation.

We thank Sir Roger Bannister and Dr Michael Swash for reading the manuscript.

Dr Clare Fowler's supported by Beaufort, France.

\section{References}

' Gosling JA. The structure of the bladder in relation to function. Urol Clin N Amer 1979;6:31-38.

${ }^{2}$ Frankssen C, Petersen I. Investigation of disturbances in the striated muscle of the urethral sphincter. Br J Urol 1955;27:154-61.

${ }^{3}$ Scott FB, Quesada EM, Cardus D. The use of combined uroflowmetry, cystometry and electromyography in evaluation of neurogenic bladder dysfunction. In The Neurogenic Bladder. Eds. Boyarsky S ed. Baltimore. Williams \& Wilkins Co. 1967.

4 Vereecken RL, Verduyn H. The electrical activity of the paraurethral and perineal muscles in normal and pathological conditions. Br J Urol 1970;42:457-63.

${ }^{5}$ Chantraine A. EMG examination of anal and urethral sphincters. In New developments in Electromyography and Clinical. Desmedt JE ed. Basel. Karger. 1973 421-32.

- Bradley WE, Scott FB, Timm GW. Sphincter electromyography. Urol Clin N Amer 1974;1:69.

' Blaivas JG, Labib KB, Bauer SB, Retik AB. A new approach to electromyography of the external urethral sphincter. J Urol 1977;117:773-77.

${ }^{8}$ Buchthal F, Pinelli L. Analysis of muscle action potentials as a diagnostic aid in neuromuscular disorders. Acta Med Scand 1953;142,Suppl 266:315-27.

${ }^{9}$ Fuglsang-Frederiksen A, Scheel U, Buchthal F. Diagnostic yield of analysis of the pattern of electrical activity of individual motor unit potentials in myopathy. J Neurol Neurosurg Psychiatry 1976;39: 742-50.

${ }^{10}$ Fuglsang-Frederiksen A, Scheel U, Buchthal F. Diagnostic yield of the analysis of the pattern of electrical activity of muscle and individual motor unit potentials in neurogenic involvement. J Neurol Neurosurg Psychiatry 1977;40:544-54.

"Czekajewski J, Ekstedt J, Stalberg E. Oscilloscopic recording of muscle fibre action potentials. The window trigger and delay unit. Electroencephalogr Clin Neurophysiol 1969;27:536-9.

${ }_{12}$ Dibenedetto M, Yalla SV. Electrodiagnosis of striated urethral sphincter dysfunction. J Urol 1979; 122:361-5.

${ }^{13}$ Gosling JA, Dixon JS, Critchley HOD, Thompson SA. A comparative study of the human external sphincter and periurethral levator ani muscles. $\mathrm{Br} \mathrm{J}$ Urol 1981;53:35-41.

14 Jesel M, Isch-Treussard C, Isch F. Electromyography of striated muscle of anal urethral sphincters. In: New Developments in Electromyography and Clinical. Desmedt JE ed. Basel. Karger. 1973:406-20.

is Neill ME, Swash M. Increased motor unit fibre density in the external anal sphincter muscle in ano-rectal incontinence: a single fibre EMG study.J Neurol Neurosurg Psychiatry 1980;43:343-7.

${ }^{16}$ Sakuta M, Nakanishi T, Toyokura Y. Anal muscle electromyograms differ in amyotrophic lateral sclerosis and Shy-Drager syndrome. Neurology (Minneap) 1978;28:1289-93. 